Supporting Information for

\title{
Evaluation of Cell Viability with Single Fluorescent Probe Based on Two Kinds of Fluorescence Signal Modes
}

Youbo Lai, Tengteng Zhang, Wenhui Song, Zihong Li, Weiying Lin *

Guangxi Key Laboratory of Electrochemical Energy Materials, Institute of Optical Materials and Chemical Biology, School of Chemistry and Chemical Engineering, Guangxi University, Nanning, Guangxi 530004, P. R. China

*Corresponding Author.

E-mail: weiyinglin2013@163.com 


\section{CONTENTS}

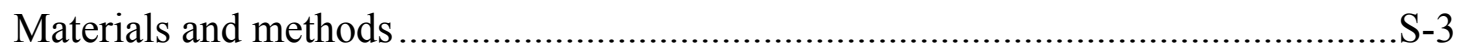

The synthesis of probes ACD-E and CHD-V ........................................................

Figure S1 Synthesis routes of the probes ACD-E and CHD-V ..............................S-3

Figure S2 The fluorescence quantum yield $\left(\Phi_{\mathrm{f}}\right)$ of the probe $\mathbf{C H D}-\mathbf{V}$.......................

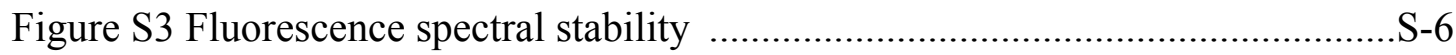

Figure S4 Theoretical calculation of probes ACD-E ................................................

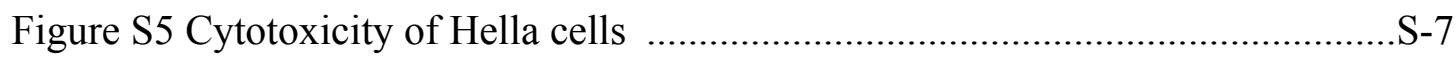

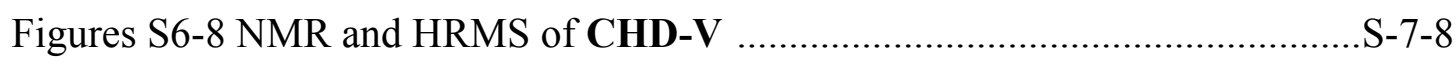

Figures S9-11 NMR and HRMS of ACD-E ................................................... $-9-10$ 


\section{Materials and methods}

All reagents were obtained from commercial suppliers without further purification. All experiments used ultra-pure water. Solvents were purified by standard methods prior. Ultra-pure water is using by ULPURE. The $\mathrm{pH}$ measurements were performed with PHS-3E pH meter. UV-vis absorption spectra were obtained on a Shimadzu UV-2700 spectrophotometer, and fluorescence spectra were measured on a HITACHI F4700 fluorescence spectrophotometer. The fluorescence imaging of cells was performed with a Leica TCS SP8 CARS confocal microscope. CCK-8 was purchased from Fluorescence imaging experiments were performed with TransGen Biotechnology. TLC analysis was carried out on silica gel plates, and column 
chromatography was conducted over silica gel (mesh 200-300); both of them were purchased from the Qingdao Ocean Chemicals. Mito-TrackerTM Red was purchased from Thermo Fisher. ${ }^{1} \mathrm{H}$ and ${ }^{13} \mathrm{C}$ NMR spectra were measured on a Varian Unity 600 spectrometer. High resolution mass spectrometric (HRMS) analyses were measured on Brooke solanX 70 FT-MS, Agilent 6540T.

\section{The synthesis of the probes ACD-E and CHD-V}

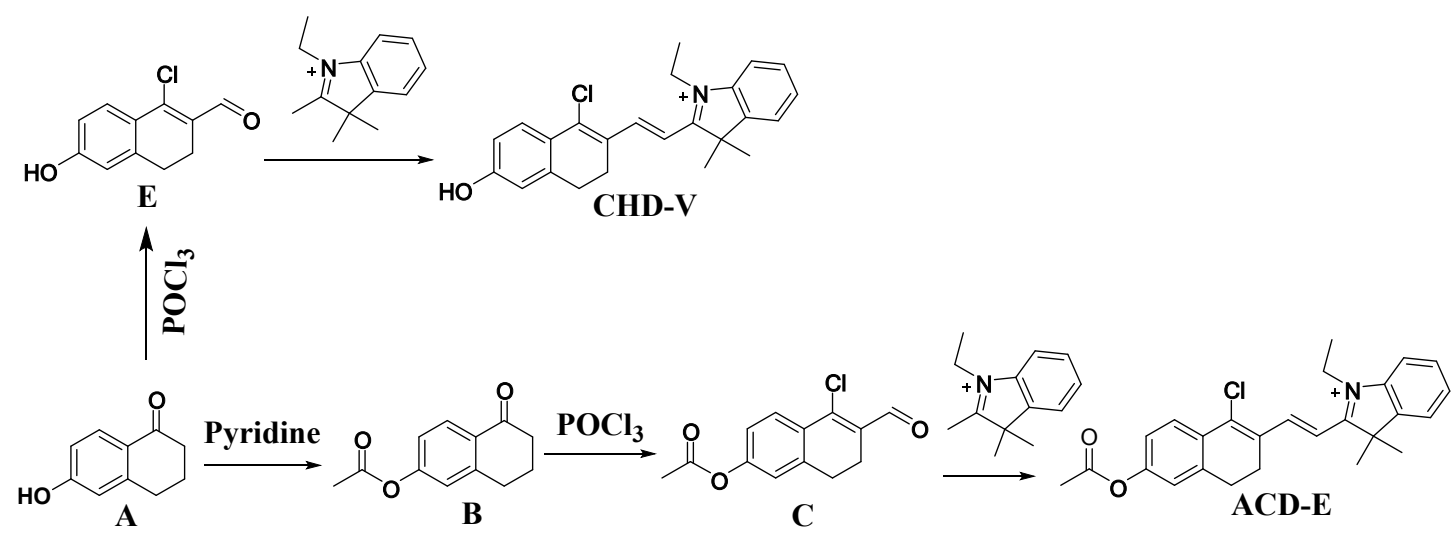

Figure S1. Synthesis routes of the probes ACD-E and CHD-V.

Characterization of compound E. Fresh $\mathrm{N}$, N'-dimethylformamide $(10 \mathrm{~mL})$ was added dropwise to phosphorus oxychloride $(2 \mathrm{~mL})$ at $0{ }^{\circ} \mathrm{C}$ temperature, and the mixture was stirred for $30 \mathrm{~min}$ to yield an orange solution. Then $370 \mathrm{mg}$ of 6-methoxytetralone ( $2.5 \mathrm{mmol}$, dissolved in $5 \mathrm{~mL}$ DMF) was added, and the solution was heated at $40{ }^{\circ} \mathrm{C}$ for 5 hours. The temperature was then raised to $70^{\circ} \mathrm{C}$ for $12 \mathrm{~h}$. After cooled to $0{ }^{\circ} \mathrm{C}$, the solution was poured onto $100 \mathrm{~g}$ of ice and neutralized by saturated sodium bicarbonate to adjust $\mathrm{pH}$ value. The crude product was purified by column chromatography on silica gel with petroleum ether and ethyl acetate as eluent to give the product as a yellow solid (137mg). ${ }^{1} \mathrm{H}$ NMR (500 MHz, DMSO- $\left.d 6\right) \delta 10.32(\mathrm{~s}, 1 \mathrm{H}), 10.19(\mathrm{~s}, 1 \mathrm{H}), 7.66(\mathrm{~d}$, $J=8.6 \mathrm{~Hz}, 1 \mathrm{H}), 6.78(\mathrm{dd}, J=8.6,2.4 \mathrm{~Hz}, 1 \mathrm{H}), 6.71(\mathrm{~d}, J=2.3 \mathrm{~Hz}, 1 \mathrm{H}), 2.78-2.69$ (m, 2H), 2.48 $(\mathrm{dd}, J=9.0,7.0 \mathrm{~Hz}, 3 \mathrm{H}) .{ }^{13} \mathrm{C}$ NMR $(126 \mathrm{MHz}, \mathrm{DMSO}-d 6) \delta 190.02,161.35,145.62,141.91$, $129.18,128.66,122.93,115.36,114.50,27.07,21.73$.

Synthesis of compound B. Product A $(2.3 \mathrm{mmol}, 400 \mathrm{mg})$ was dissolved in anhydrous pyridine $(10 \mathrm{~mL})$, and then acetic anhydride added dropwise slowly at $0{ }^{\circ} \mathrm{C}$ under a nitrogen atmosphere. Mixture warm to room temperature, then the solution was refluxed stirred at $110{ }^{\circ} \mathrm{C}$ overnight (the reaction was monitored by a TLC plate), then cooled, pour the reactants into ice water. The solution extract $20 \mathrm{~mL} * 3$ with ethyl acetate, and then add copper sulfate solution. Solvent was removed under reduced pressure and purified by column chromatography with a gradient elution $(\mathrm{CH} 2 \mathrm{Cl} 2)$ to give the product $\mathrm{B}$ as a white solid. (357 mg) ${ }^{1} \mathrm{H}$ NMR $(500 \mathrm{MHz}$, DMSO-d6) $\delta 7.91(\mathrm{~d}, J=8.5 \mathrm{~Hz}, 1 \mathrm{H}), 7.32-6.84(\mathrm{~m}, 2 \mathrm{H}), 2.95(\mathrm{t}, J=6.0 \mathrm{~Hz}, 2 \mathrm{H})$, $2.66-2.55(\mathrm{~m}, 2 \mathrm{H}), 2.14-1.97(\mathrm{~m}, 2 \mathrm{H})$. 
Synthesis of compound $\mathrm{C}$. The compound $\mathrm{C}$ was synthesized according to produce E procedure. 1H NMR (500 MHz, DMSO-d6) $\delta 10.27(\mathrm{~s}, 1 \mathrm{H}), 7.86(\mathrm{~d}, \mathrm{~J}=$ $8.4 \mathrm{~Hz}, 1 \mathrm{H}), 7.19$ (dd, J = 8.4, $2.4 \mathrm{~Hz}, 1 \mathrm{H}), 7.17$ (s, 1H), 2.85 (s, 3H), 2.56 (d, J = 8.3 $\mathrm{Hz}, 2 \mathrm{H}), 2.30$ (s, 3H). 13C NMR (126 MHz, DMSO-d6) $\delta$ 190.52, 169.37, 153.14, $143.89,141.18,132.25,129.33,127.75,121.88,121.07,26.53,21.58,21.33$

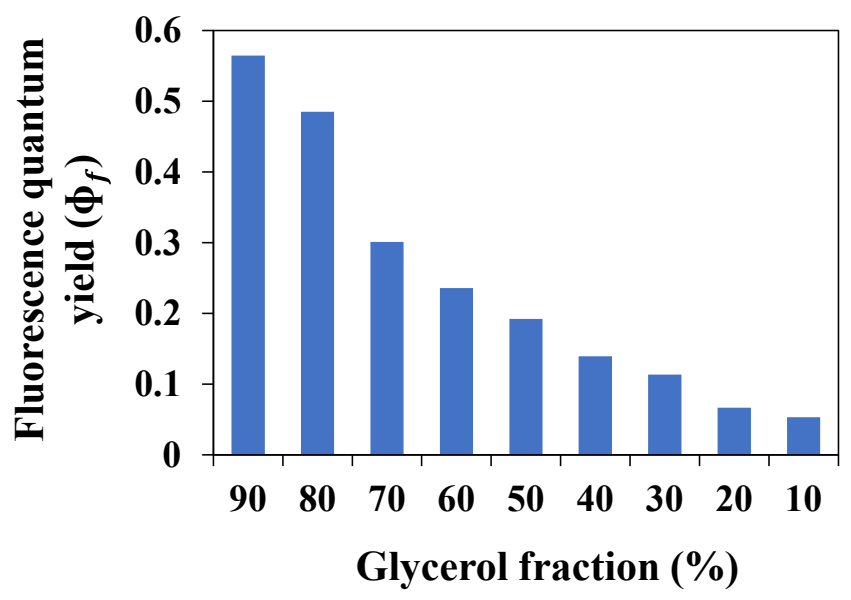

Figure S2 The fluorescence quantum yield $\left(\Phi_{\mathrm{f}}\right)$ of the probe $\mathbf{C H D}-\mathbf{V}$ in different ratio of ethanol and glycerol.

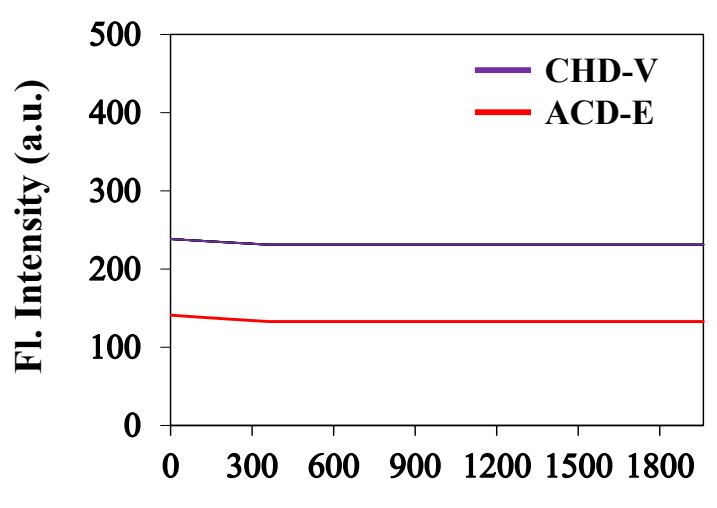

Time (min) 
Figure S3 The intensity of fluorescence spectra of probe CHD-V $(10 \mu \mathrm{M})$ at $698 \mathrm{~nm}$ in EtOH and ACD-E $(10 \mu \mathrm{M})$ at $609 \mathrm{~nm}$ in EtOH/PBS $(1: 20, \mathrm{v} / \mathrm{v})$ in different time at room temperature.

(a)

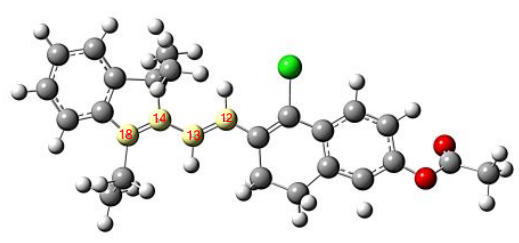

(b)

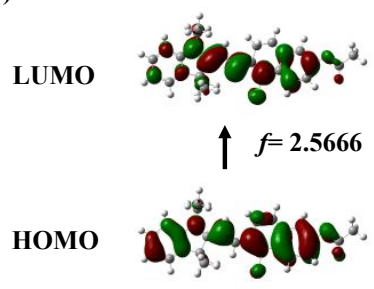

(c)

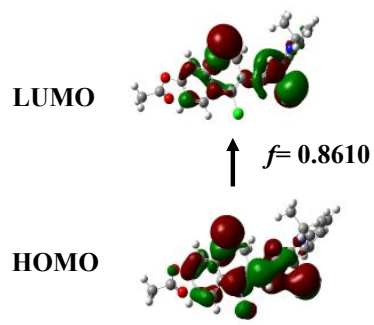

Figure S4 (a) The optimized geometries of ACD-E in the excited states; (b) the frontier molecular orbital of ACD-E in the excited states with a dihedral angle of $0^{\circ}$ at around $\mathrm{C} 12-\mathrm{C} 13-\mathrm{C} 14-\mathrm{N} 18$; (c) the frontier molecular orbital of ACD-E in the excited states with a dihedral angle of $90^{\circ}$ at around C12-C13-C14-N18. Calculations were performed by the DFT method (PCM model) with a B3LYP/6-31G $(\mathrm{d}, \mathrm{f})$ basis set using Gaussian 09. 


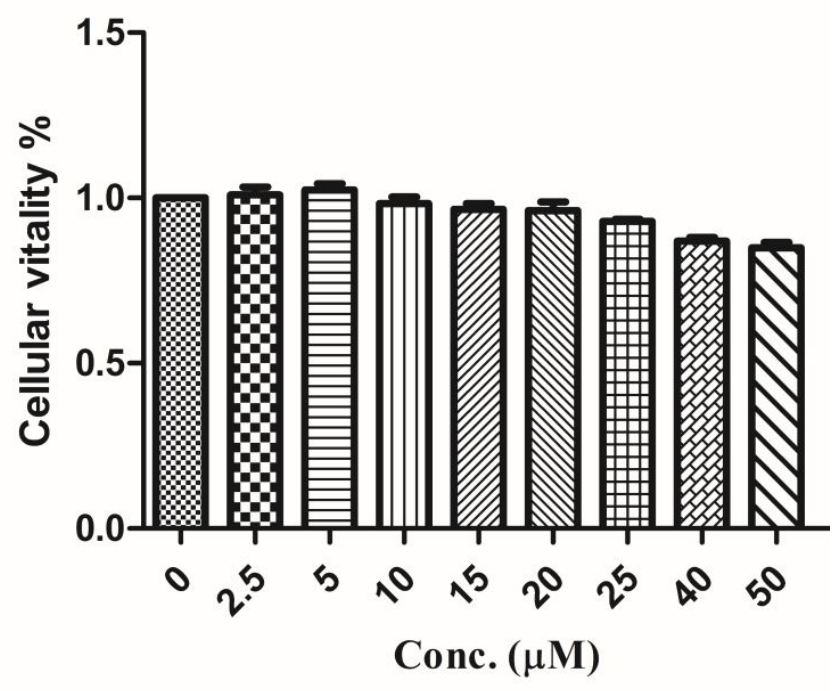

Figure S5. Effects of the probe ACD-E with varied concentrations $(0-50 \mu \mathrm{M})$ on the viability of the Hela cells. The probe with varied concentrations was incubated with the cells for $24 \mathrm{~h}$. The viability of the cells in the absence of the probe is defined as $100 \%$, and the data are the mean standard deviation of five separate measurements.

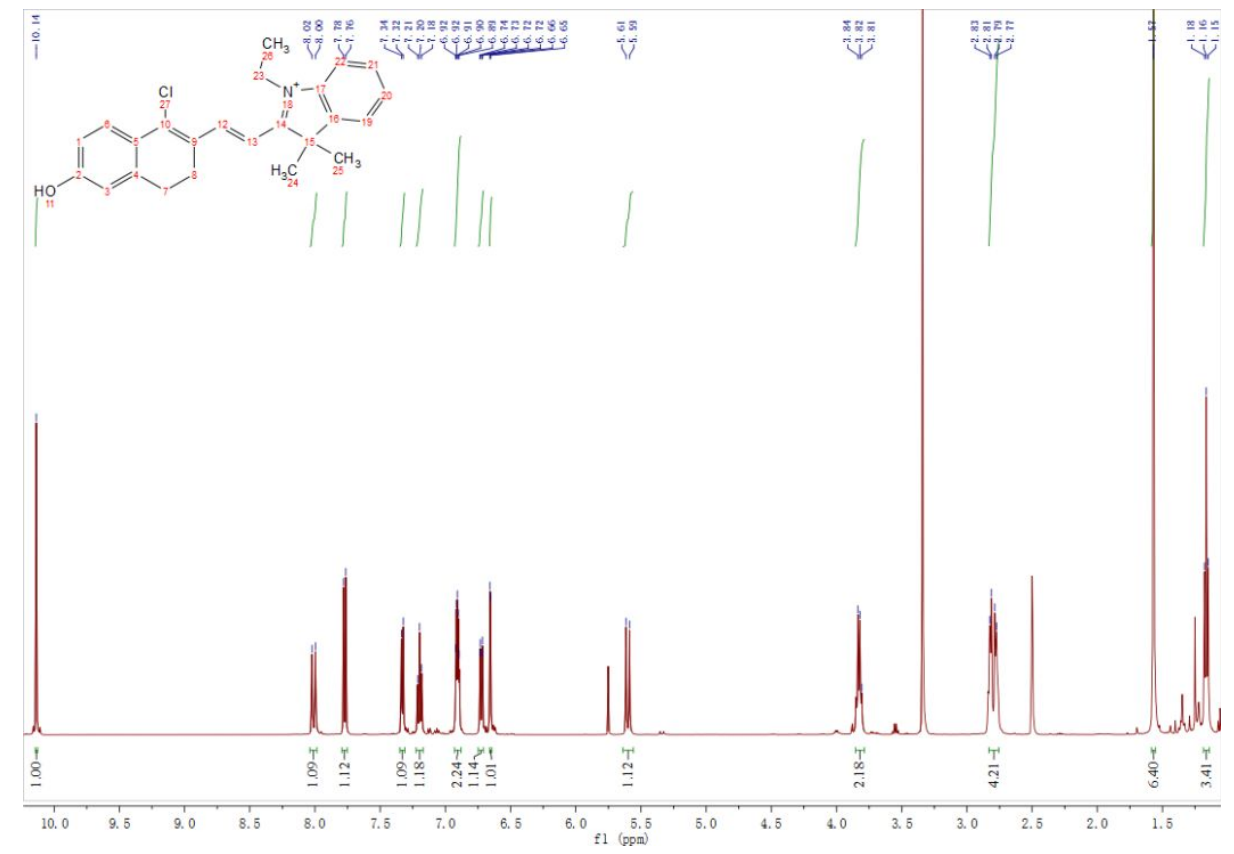

Figure S6 ${ }^{1} \mathrm{H}$ NMR spectra of probe $\mathbf{C H D}-\mathbf{V}$ in DMSO- $d 6$. 


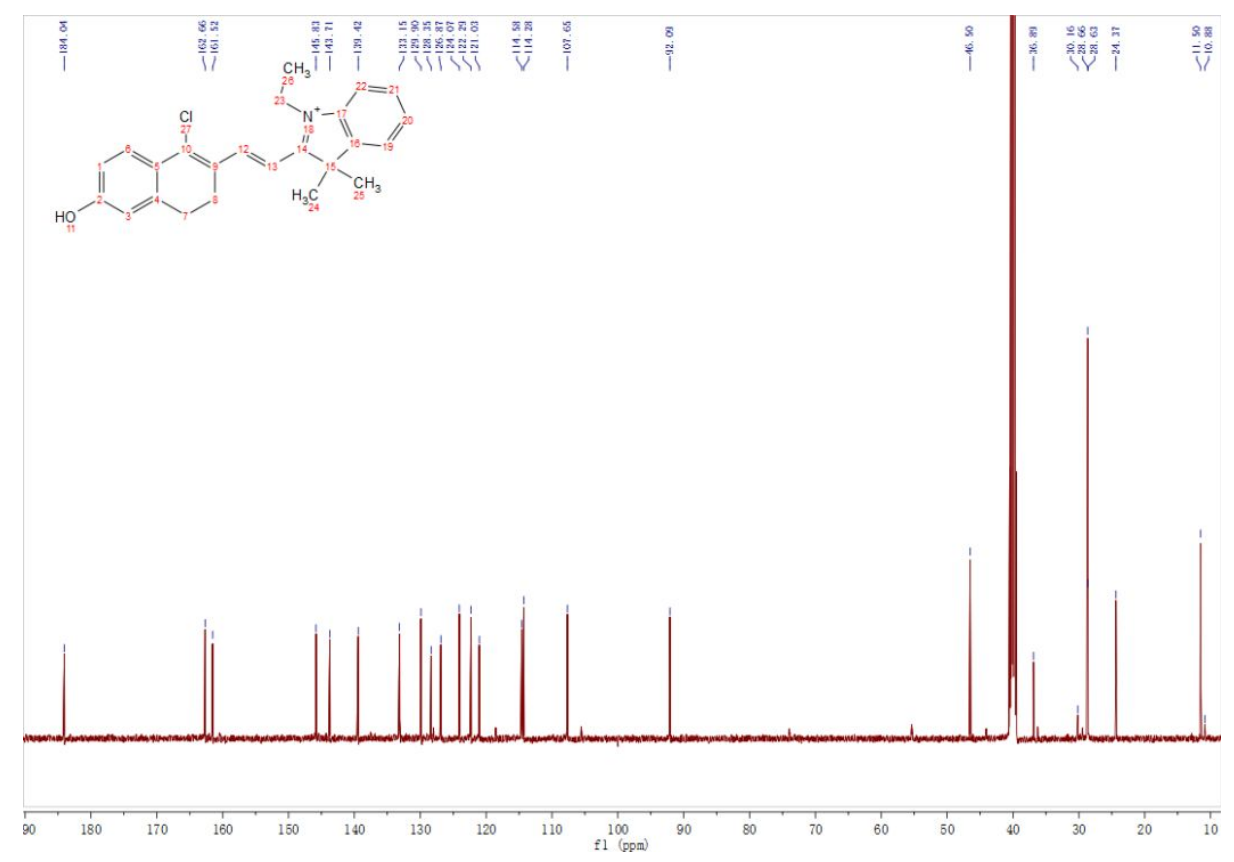

Figure S7 ${ }^{13} \mathrm{C}$ NMR spectra of probe $\mathbf{C H D}-\mathbf{V}$ in DMSO- $d 6$. 


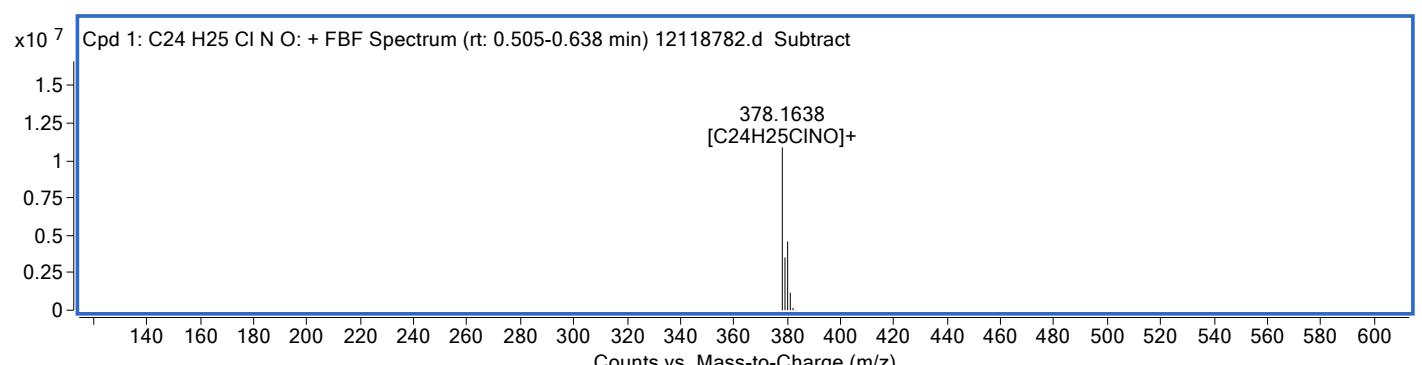

Figure S8 HRMS spectrum of CHD-V

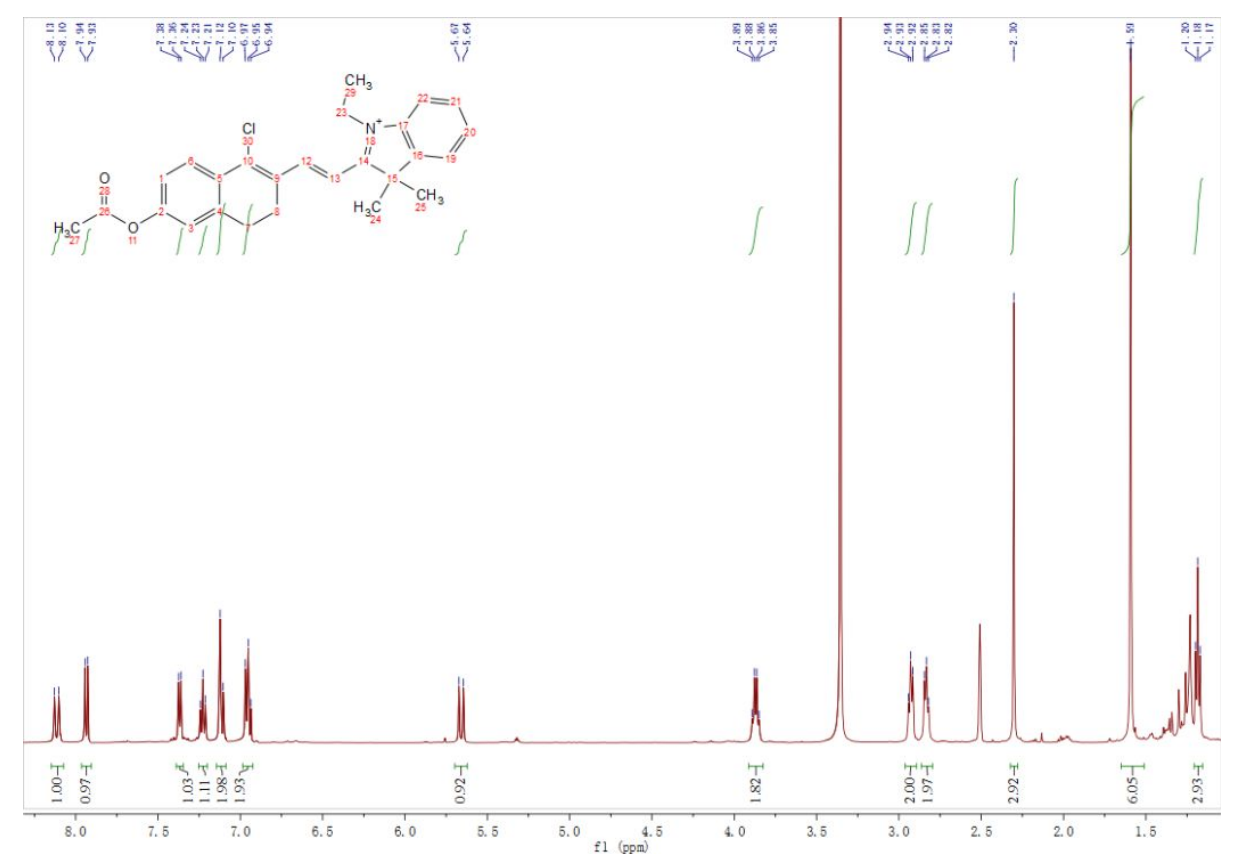

Figure S9 ${ }^{1} \mathrm{H}$ NMR spectra of probe ACD-E in DMSO- $d 6$. 


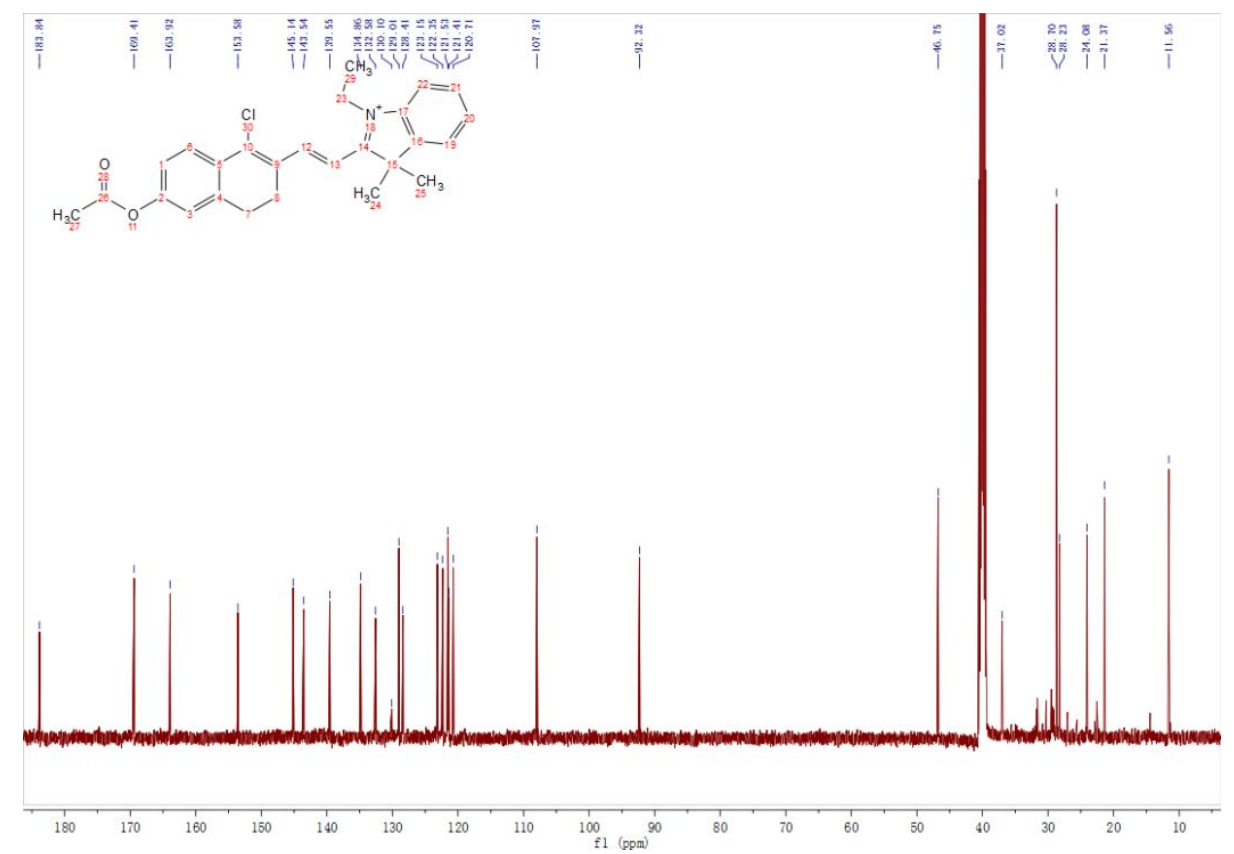

Figure S10 ${ }^{13} \mathrm{C}$ NMR spectra of ACD-E in DMSO- $d 6$.

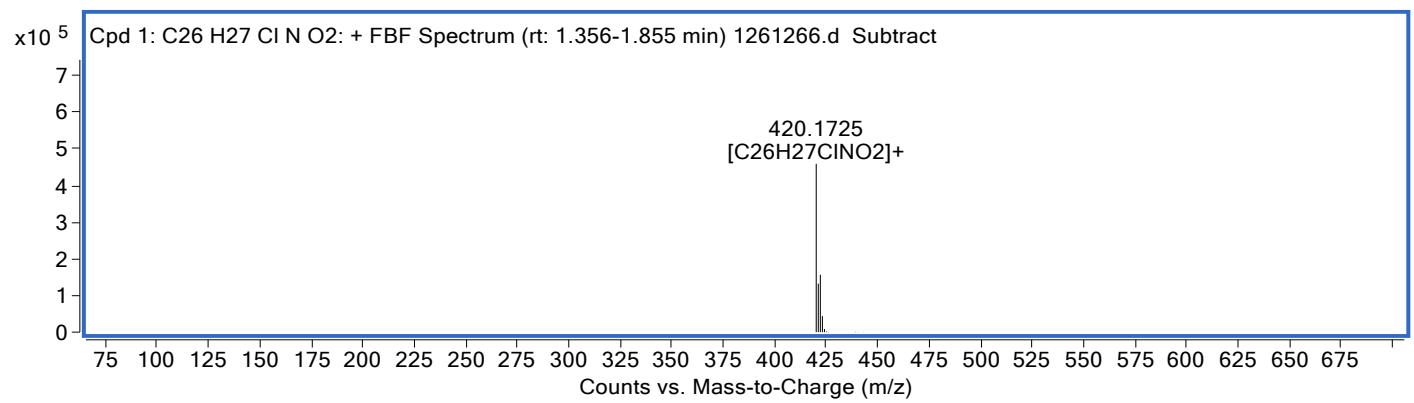

Figure S11 HRMS spectrum of ACD-E 